\title{
Married men's perceptions of barriers for HIV- positive pregnant women accessing highly active antiretroviral therapy in rural Uganda
}

This article was published in the following Dove Press journal:

International Journal of Women's Health

15 May 2012

Number of times this article has been viewed

\author{
Putu Duff' \\ Tom Rubaale ${ }^{2}$ \\ Walter Kipp ${ }^{1,2}$ \\ 'School of Public Health, University \\ of Alberta, Edmonton, Canada; \\ ${ }^{2}$ Community ARV Project, Fort \\ Portal, Uganda
}

Correspondence: Walter Kipp Professor of Global Health, Department of Public Health Sciences, School of Public Health, 3-50F University Terrace, 303-I I 2 Street, University of Alberta, Edmonton, Alberta, Canada

Tel +l 7804928643

Fax +I 7804920364

Email walter.kipp@ualberta.ca
Background: The aim of this study was to describe the perceptions of married men about barriers to accessing and accepting highly active antiretroviral therapy (HAART) by pregnant/ postnatal women positive for human immunodeficiency virus (HIV) and registered in Kabarole District's Program for the Prevention of HIV from Mother to Child (PMTCT-Plus).

Materials and methods: Our study was a qualitative descriptive exploratory study using thematic analysis. Four focus group discussions were held with a convenience sample of 40 married men.

Results: Lack of disclosure of a positive HIV diagnosis to the partner and stigmatization of persons with HIV were two major obstacles for women in accessing HAART. In addition, men felt that their low knowledge of HAART and their low HIV testing rate also constituted important barriers to these women taking treatment. Men complained that they were not sufficiently involved in the reproductive care of women and that couples' counseling could be a step towards addressing this problem.

Conclusion: Barriers to HAART experienced by pregnant/postnatal women need to be addressed in order to improve their uptake of treatment, increase their low treatment coverage, improve their survival, and at the same time dramatically reduce HIV transmission from mother to child.

Keywords: men, highly active antiretroviral therapy, pregnant women, Uganda

\section{Introduction}

Factors that hinder access to highly active antiretroviral therapy (HAART) among both men and women living in sub-Saharan Africa have been well described. Barriers to accessing HAART among men and women identified in the literature included cost of transportation to the clinic, other treatment costs, complicated HAART regimes, language barriers between patients and health staff, adverse reactions to HAART, overcrowded health care systems, overworked clinic staff, and lack of knowledge about HAART procedures. ${ }^{1-7}$

HAART coverage for pregnant women in developing countries is much lower compared with that of the general population of patients with human immunodeficiency virus (HIV) and is reported to be only $15 \% .{ }^{8}$ Similarly, although HAART coverage of all eligible HIV patients in Uganda is 43\%, ${ }^{8}$ only 7082 (17\%) of 46,948 eligible pregnant women in Uganda received HAART in 2008-2009. ${ }^{9}$ In an effort to expand HAART uptake by pregnant/postnatal women and to reduce mother-to-child transmission of HIV, the Ugandan PMTCT-Plus (Prevention of Mother to Child Transmission of HIV) program was established. The PMTCT program consists of free 
HIV counseling and testing, single-dose nevirapine and/or free HAART to eligible HIV-positive mothers and family members, using eligibility criteria according to the national guidelines for HAART. ${ }^{10}$ Despite the Ugandan government's efforts to scale up PMTCT-Plus programs from 2003 to 2006 , Uganda data included in the last country report on HIV/AIDS in 2010 indicate that HAART coverage remains low in pregnant/postnatal women attending PMTCT-Plus clinics, resulting in 25,000 new pediatric HIV infections nationwide due to mother-to-child transmission in 2008. ${ }^{11}$

Few studies involving pregnant/postnatal women have reported reduced access to HAART or refusal to utilize HAART compared with nonpregnant/postnatal women, or men. ${ }^{5,12,13}$ Also of importance is that very little is known about the male perspective on PMTCT and the role men play in their partners' HAART access and uptake. ${ }^{14,15}$ This is particularly important in traditional patriarchal subSaharan African societies, and particularly in Uganda, where men are often responsible for household decisions, including health-related and health-seeking behaviors for their dependent wives and children. Therefore, it is crucial to understand men's perceptions about HAART and its benefits, especially for pregnant women, given its potential to reduce mother-to-child transmission of HIV. Two studies from Uganda and Tanzania reported male involvement in components of the PMTCT program, ${ }^{14,15}$ and concluded that male involvement in PMTCT programs was low, and that there was an urgent need to explore male perceptions of PMTCT services further. Despite this, our PubMed search revealed no studies that investigated men's perception of HAART services for pregnant/post-natal women in sub-Saharan Africa, which increases the importance of the study we have conducted.

To address this gap in knowledge surrounding barriers to accessing HAART among pregnant/postnatal women, we undertook a study in Kabarole District, western Uganda, between September 2006 and December 2006, with a sample of men from urban and rural areas. This study component was part of a larger study investigating barriers to HAART uptake by pregnant women from the viewpoint of women and men. ${ }^{16}$ In the quantitative part focusing on women's barriers, economic reasons (primarily high transport costs), followed by HIV-related stigma, nondisclosure of HIV status between partners, long clinic waiting times, and suboptimal provider-patient interactions at the PMTCT-Plus clinic were reported. The qualitative study presented here sought to expand upon our previous findings by reporting men's perspective on the issue.
The two specific objectives of our study were to explore and describe the views of married men on barriers to free HAART among pregnant/postnatal women in Kabarole District and to analyze the main reasons for low HAART uptake among pregnant/postnatal women from the perspective of married men and contrast the responses from men with the responses from women given in the quantitative study component. ${ }^{16}$

\section{Materials and methods}

Our study was a qualitative descriptive exploratory study with thematic analysis. Data were collected through four focus group discussions with 40 participants. Utilizing a qualitative methodology, we undertook extensive discussions among participants that revealed men's perceived barriers to HAART access by their female partners in a way that may not have been obtained from solely quantitative methodologies.

\section{Study setting}

Kabarole's PMTCT-Plus programs were first launched in 2003 in five hospitals in the district. These hospitals are attended by 13,000 women per year, approximately $8 \%$ of whom are HIV-positive. Kabarole District's PMTCT-Plus program at the regional hospital experiences a low uptake of HAART among eligible PMTCT-Plus clients, with approximately one quarter of the clients on HAART lost to follow-up in 2006, according to information from the District Health Office. Kabarole District has an estimated population of 400,000, approximately 20,000 of which are pregnant women at any given point in time.${ }^{17}$ The district's population is characterized as low-income, with subsistence farming representing the main source of income. Approximately $74 \%$ of the population resides in rural areas, distant from urban hospitals and health clinics.

\section{Study sample}

Forty participants for the four focus group discussions were selected by convenience sampling from both urban and rural areas. Inclusion criteria for the focus group discussions were being male and married or having a female partner within the 18-45-year age group. Participants were fully briefed on the study prior to enrollment. Demographic information for the participants is shown in Table 1. The local administration provided a quiet interview space for focus group discussions to avoid noise interference and interruptions.

\section{Study instrument}

The focus group discussion guide topics were derived with input from the literature and the knowledge/perceptions 
Table I Demographic characteristics of 40 male focus group discussion participants

\begin{tabular}{lllll}
\hline & Group I & Group 2 & Group 3 & Group 4 \\
\hline $\begin{array}{l}\text { Participants, n } \\
\begin{array}{l}\text { Mean (range) } \\
\text { age, years }\end{array}\end{array}$ & $28(18-35)$ & $32(19-4 \mid)$ & $28(18-40)$ & $28(18-39)$ \\
\begin{tabular}{l} 
Residence \\
\hline
\end{tabular} & Urban & Urban & Rural & Rural \\
\hline
\end{tabular}

of local health care workers involved in the PMTCT-Plus program. Discussion topics included knowledge of HIV and HAART, willingness to be tested for HIV, HIV serostatus disclosure between partners, social support, and perceived reasons for the low uptake of free HAART by pregnant/ postnatal women. The participants were not asked about their own HIV status. It was also made clear to the participants before the focus group discussions started, that the topic of discussion was not single-dose nevirapine, but lifelong antiretroviral combination drug therapy, ie, HAART.

\section{Data collection and analysis}

The focus group discussions were conducted using the interview guide, developed with open-ended questions. The focus group discussions were moderated by the first author with a research assistant experienced in qualitative methodology, who provided simultaneous translation from Rutooro (the local language) into English. The interviews were audiotaped with the consent of the participants. The focus group discussions lasted on average about 80 minutes each. Tapes were transcribed verbatim in Rutooro and were subsequently translated into English. Spot checks of transcripts and translations were regularly conducted to ensure completeness of the transcription and accuracy of translation.

Data analysis for the focus group discussions was conducted using principles of thematic analysis. ${ }^{18,19}$ This included multiple overall surface readings of transcripts to capture context and meaning, followed by coding and categorization of recurring concepts/ideas. A master list of all categories was assembled and examined for common themes. Categories of codes were then organized into overarching themes. Data verification was done by a second researcher coding all transcripts. Codes were compared and added or removed based by agreement. The results of our interviews were also compared with the literature and verified with participants. Following coding, a frequency distribution list was developed, and the number of responses for each category of participants was recorded and tallied. Quotations selected were those which best represented the ideas voiced by participants and were also chosen based on the frequency with which they were mentioned.

\section{Ethical considerations}

Ethical and administrative approval of the study methodology was sought and granted from the Health Research Ethics Board at the University of Alberta, Edmonton, Canada, the Ugandan Council for Science and Technology, Kampala, Uganda, and the District Health Officer, Kabarole District, Fort Portal, Uganda. Informed consent was obtained from each participant prior to the interview by reading and providing an information letter and signing a consent form. Participants received a small amount (between $\$ 1$ and \$2) to assist with transport to participate in the study.

\section{Results}

The four main themes extracted from the data were lack of HAART knowledge among males, low HIV testing in males, women's lack of trust in confidentiality when on HAART, and fears of serostatus disclosure to their partners.

\section{Lack of HAART knowledge among males}

Although most study participants were cognizant of HAART, their level of knowledge seemed to be very basic and incomplete. There were about one or two participants in each focus group who had never heard of HAART before. The following focus group discussion excerpts exemplify the typical responses obtained regarding HAART knowledge:

"Advise us about HAART. Some of us we don't know anything about these drugs, so teach us so we can know something."

"Women are sensitized when they go for antenatal care.

Men should also be sensitized by all means so they can test."

Misconceptions about HAART were also expressed, eg, that antiretroviral drugs cause weakness sometimes leading to death of HIV patients. This common misconception was mentioned by multiple respondents in all four of the male interviews, as indicated in the following passage: "[People] said that when you start on these drugs and then you stop you can even die and this is one of the reasons as to why people have feared to go and test to get the drugs."

The most common question raised in all four focus group discussions was whether or not HAART cures HIV/acquired immune deficiency syndrome (AIDS):

"We hear that [HAART] reduces the virus in the body and you live a bit longer but what I don't know is whether it totally cures AIDS so I beg you to explain more and let us know the truth about these drugs." 
"If I am 30 years old but the disease has eaten me up and I am only left with maybe two years to die, if I start taking those drugs, will I be cured?"

Many respondents articulated that, unlike women, who are counseled in antenatal clinics, men lack the opportunity to be taught about HIV/AIDS and HAART.

\section{Low HIV testing among men}

Many respondents felt that a lack of HIV/AIDS and HAART knowledge among men may contribute to their low uptake of HIV testing. In addition, economic reasons for not being HIV tested were mentioned, as shown in the following responses:

"Some of us don't have transport and we hesitate going to far places for testing."

"Even there at the sub-county health unit they charge two thousand five hundred shillings (approximately \$1 US) per head. So if you are to go with your wife that's five thousand, which we don't have - that also makes us reluctant. We have other problems and requirements at home."

The latter excerpt expresses a sentiment that was repeated by many other respondents, ie, that being tested interferes with their ability to work and is often regarded as a nuisance rather than a priority. The following comment by one participant implies that an HIV-positive diagnosis resulting from testing creates worries that can also interfere with one's ability to work:

"Men do a lot of hard work - working from morning until late in the evening, so they say when they test and maybe they are HIV-positive they will have many worries and they will not be able to work. That is why they don't test."

\section{Women lack trust in confidentiality when on HAART}

Our results suggest that participants were well aware of men's influence on their partners' decision to take HAART. Men also speculated that HAART uptake by pregnant/postnatal women may avoid taking HAART to conceal their HIVpositive diagnosis from their partners, as follows:

"The woman fears maybe because she still loves the husband and maybe they have children so she decides to keep quiet to avoid conflicts at home because she fears the man might say she is the one who brought the disease."

"Some women are beaten by their husbands at times for no good reason if then he saw you swallowing drugs, he'd kill her."
Fear of violence as a barrier to disclosure and HAART acceptance was cited by several participants. Participants also explained that, because many women depend on their partners for economic support, abandonment as a result of an HIV-positive status disclosure would eliminate this monetary resource on which they rely for survival:

"She fears if the man comes to know about it, she can divorce her and you know people are poor, she will start suffering with no-one to help her. Poverty is the problem. If someone knows she can support herself without the man then she can start the drugs without even telling the husband."

Another factor that men indicated may inhibit women from disclosing their status or taking HAART is fear of being identified as an AIDS patient by community members, as indicated in the following: "People fear being identified because if they saw her at the clinic then people will start saying so and so family is all sick."

\section{Fear of serostatus disclosure}

Many men indicated that they would withhold a positive diagnosis from their partners. A few men explained that if diagnosed positive, partner disclosure would be contingent on their partner's diagnosis. They explained that if their partner revealed a discordant diagnosis, they would be more likely to keep their positive status a secret:

"For me I was thinking that maybe I can go for testing first before the woman goes there and I test HIV-positive and I fear to tell her and when she goes there afterwards and she tests HIV-negative, then for me I will fear to tell her.

I may inform her [of my HIV-positive status], and I put all my trust in her but when she goes and tests and finds herself HIV-negative, as I trust her I may not tell her instead I will keep on using a condom."

Both respondents above communicated that the act of disclosure to be reliant upon their partner's diagnosis. These comments implicitly assume that partners are not very open about their test results, and perpetuate secrecy between partners and compromise treatment uptake. Most men also cited a fear of abandonment as the primary motivation for partner nondisclosure:

"I can't tell her, she will run away and leave me with the children."

"If you the man brought the idea of testing, the woman will say that it means you are sick. She will start suspecting you to be HIV positive and she might even run away from you." 
The most common solution offered was that couples should be counseled and tested together. Participants suggested that this would promote understanding and reduce nondisclosure among couples:

"For me I say there should be an understanding between the two and they both test and in case they are both sick of this disease they start the treatment."

"I think with this issue of testing - it is better the two people be true to each other, both go and test and if they are to start the dose they both start that can benefit both of them."

When we compared these responses about barriers to HAART uptake with those already published for women, ${ }^{16}$ both groups agreed that the stigma of HIV and risk of disclosure of the diagnosis were formidable barriers to HAART access and uptake by pregnant/postnatal women. However, we also observed striking differences in their responses on what constituted barriers to HAART. Economic factors were at the top of the women's list, whereas this barrier was not significant for men. Women also mentioned barriers for HAART access were their personal well being, eg, being too sick to go to the clinic or the belief that if they do not have clinical symptoms due to HIV, they do not need HAART. Health care-related factors constituting barriers to HAART, such as long waiting times at the clinic and unfriendly staff, did not feature in the male focus group discussions. While men tended to dwell on their low HAART knowledge, women did not mention this at all. Furthermore, lack of involvement in pregnancy and reproductive issues on the part of men was not referred to by the women. Similarly, joint counseling of both male and female partners during prenatal clinic visits was an important strategy for education about HAART expressed by men, but was not expressed by women in our previous study.

\section{Discussion}

This exploratory qualitative study provides an insight into the male perspective on the cultural context of locally perceived barriers to accessing HAART by pregnant/postnatal women attending the PMTCT-Plus program at the main regional hospital in Kabarole District.

Considering the drastically low coverage of HAART treatment among pregnant/postnatal women in Uganda and other developing countries, this study addresses a high priority research/knowledge gap in HIV/AIDS care and prevention. Given that pregnant/postnatal women who are successful on HAART have significant health benefits, as well as a reduced risk of transmitting HIV to their offspring, ${ }^{20-22}$ the benefits of this program are multiple. Extending beyond the well being of infants and family members, this program is a huge investment in the health of women themselves. This study is one of few that have investigated both male and female perceptions of HAART treatment in the context of one selected PMTCT-Plus program. This approach enabled us to contrast male and female responses and provide a more indepth description on issues surrounding the low uptake of HAART by pregnant/postnatal women in this area.

Lack of knowledge on the part of men about HAART and services for pregnant/postnatal women was expressed by all participants, and was always a source of complaint in the discussions. This finding reflects the fact that although men are often excluded from reproductive health programs and counseling, they have a strong desire to be included in these services. This is also supported by men's suggestion for couples counseling in PMTCT-Plus clinics, which may not have been effectively promoted in the study region. This willingness to participate is consistent with other studies from Uganda and East Africa. ${ }^{14}$ Surprisingly, although fear of HIV serostatus disclosure to one's partner frequently surfaced as a barrier to HAART for pregnant/postnatal women in our study, ${ }^{16}$ lack of couples counseling was not identified as an issue by women. Lack of couples counseling in PMTCT-Plus programs has been identified mainly as a shortcoming on the part of service providers, ${ }^{23-25}$ but our findings suggest that women themselves may not view it as a deficit, although men do.

The main barrier to uptake of HAART by pregnant women expressed by men was fear of serostatus disclosure to their partners. They explained that women may find it impossible to hide their medication from their partners at home nor could they avoid being seen by neighbors or friends at the HAART clinics. This indicates that if an atmosphere of distrust in regard to HIV infection exists between partners, women may opt out of treatment because they see the risk of being identified as HIV-positive as too high. While stigmatization against persons with HIV has declined in the study area, it is still a reminder that stigma against HIV remains a serious impediment to HAART uptake among HIV-infected persons. The fear of disclosure of a positive HIV status to a partner was discussed thoroughly in all the focus group discussions and was believed to be widely prevalent, which is consistent with the literature. ${ }^{14,15,26,27}$

Comparison of our male and female study respondents revealed two surprising results. Men reported a strong desire to be involved in reproductive services, such as HIV testing and HAART for pregnant/postnatal women. In contrast, in the women's interviews, male participation was completely 
absent from the discussion surrounding barriers to HAART. It was the men, rather than the women, who wanted increased opportunities for men's involvement in voluntary testing and couples counseling for HIV and PMTCT-Plus. These results raise a few larger questions.

Could it be that women do not want men to be part of their reproductive care and instead prefer to keep it as a women's issue? Or could it be that this question of male involvement was never explored with women, and women assume that men do not want to attend PMTCT counseling or reproductive health care services? Given that health services struggle to involve more men in female reproductive health care mainly by reorienting and retraining health care providers, ${ }^{23-25}$ the more important step could be to educate, discuss with, and sensitize women towards the goal of reproductive care in which both the male and female partner take part and share responsibilities. This important question warrants further investigation, and the results should be considered when developing educational programs for HIV treatment and prevention.

Given HIV/AIDS disclosure for pregnant women is so very risky (eg, abuse or abandonment), is couples counseling at the pregnancy stage already too late? We should aim for couples counseling on reproductive health, including disclosure of HIV serostatus, well before a woman has to cope with pregnancy in a relationship. These findings reinforce our previously published recommendations that the earlier HAART education, treatment, and couples counseling can be provided, the better. Accelerating the uptake of HAART among pregnant women is critical, given the current suboptimal HAART coverage among pregnant/ postnatal women in Uganda and elsewhere.

The importance of dealing with nondisclosure of an HIV-positive status in couples in this cultural setting has to be fully recognized. It is likely that intervention at the individual level (education) and interpersonal level (couples counseling) alone may not be sufficient to achieve any improvement. Intervention at the societal/structural level by education programs in communities at large is also required to improve societal acceptance of persons living with HIV, to enhance spousal responsibility for their partner's health, to promote gender equality, and to counteract cultural beliefs about reproductive care being solely the responsibility of women.

\section{Limitations}

Because this was a qualitative study, the results cannot be generalized to populations outside of the Ugandan context.
Secondly, given the sensitive nature of the topic, social desirability bias cannot be excluded. Interviewers trained in qualitative methods were used to reduce this potential bias. Finally, our data were collected in 2006, although given that little has changed in regard to HAART treatment for pregnant women since then, the results of this study continue to be relevant.

\section{Conclusion}

This study is very important for operational direction and improvement in service delivery since no other literature is available on this topic in sub-Saharan Africa. As a society, if men were more involved in reproductive health with their partners, and women would accept this approach, then couples could realize the significant benefits of a healthier, open approach to reproduction, including improved uptake of PMTCT-Plus services.

\section{Acknowledgments}

We thank Jean Kipp for her very useful comments on the early drafts of the manuscript. The study was financed by a research grant from the Canadian Institutes of Health Research (MOP-74586) and the Fund for Support of International Development Activities, University of Alberta, Edmonton, Canada.

\section{Disclosure}

The authors report no conflicts of interest in this work.

\section{References}

1. Mshana GH, Wamoyi J, Busza J, et al. Barriers to accessing antiretroviral therapy in Kisesa, Tanzania: a qualitative study of early rural referrals to the national program. AIDS Patient Care STDs. 2006;20(9):649-657.

2. Tuller DM, Bangsberg DR, Senkungu J, Ware NC, Emenyonu N, Weiser SD. Transportation costs impede sustained adherence and access to HAART in a clinic population in southwestern Uganda: a qualitative study. AIDS Behav. 2010;14(4):778-784.

3. Hounton S, Akonde A, Zannou D, Bashi J, Meda N, Newlands D. Costing universal access of highly active antiretroviral therapy in Benin. AIDS Care. 2008;20(5):582-587.

4. Giuliano M, Vella S. Inequalities in health access: access to treatment for HIV/AIDS. Ann Ist Sup Sanita. 2008;43(4):313-316.

5. Makombe S, Libamba E, Mhango E, et al. Who is accessing antiretroviral therapy during national scale-up in Malawi? Trans R Soc Trop Med Hyg. 2006;100(10):975-979.

6. Grant E, Logie D, Masura M, Gorman D, Murray S. Factors facilitating and challenging access and adherence to antiretroviral therapy in a township in the Zambian Copperbelt: a qualitative study. AIDS Care. 2008;20(10):1155-1160.

7. Posse M, Meheus F, van Asten H, van der Ven A, Baltussen R. Barriers to access to antiretroviral treatment in developing countries: a review. Trop Med Int Health. 2008;13(7):904-913.

8. UNAIDS. Uganda 2010 progress report on HIV/AIDS. Available from: http://data.unaids.org/pub/Report/2010/uganda_2010_country_progress_report_en.pdf. Accessed March 1, 2012. 
9. Government of Uganda. Ungass country progress report Uganda. January 2008-December 2009. March 2010, Kampala, Uganda. Available from: http://data.unaids.org/pub/Report/2010/uganda_2010_country_progress_report_en.pdf. Accessed March 1, 2012.

10. Uganda Ministry of Health. Policy for reduction of the mother to child HIV transmission of HIV in Uganda, 2006. Revised Edition Kampala, Uganda. Available from: http://www.idi.ac.ug/docs/Policy\%20\%20 PMTCT\%202003.pdf.

11. Elyanu P. Current status of paediatric HIV in Uganda. Report of the Republic of Uganda, 2008. Available from: http://www.upa.or.ug/ dloads/2.\%20Situation $\% 20$ of $\% 20$ paed $\% 20 H I V \% 20$ services $\% 20 . N P C$. pdf. Accessed March 29, 2012.

12. Murray LK, Semrau K, McCurley E, et al. Barriers to acceptance and adherence of antiretroviral therapy in urban Zambian women: a qualitative study. AIDS Care. 2009;21(1):78-86.

13. Mbonye AK, Hansen KS, Wamono F, Magnussen P. Increasing access to prevention of mother-to-child transmission of HIV services through the private sector in Uganda. Sex Transm Infect. 2009,85(7):534-539.

14. Falnes EF, Moland KM, Tylleskar T, de Paoli MM, Msuya SE, Engebretsen IM. "It is her responsibility": partner involvement in prevention of mother to child transmission of HIV programmes, northern Tanzania. J Int AIDS Soc. 2011;14(1):21.

15. Byamugisha R, Tumwine JK, Semiyaga N, Tylleskar T. Determinants of male involvement in the prevention of mother-to-child transmission of HIV programmes in Eastern Uganda: a cross-sectional survey. Reprod Health. 2010;7:12.

16. Duff C, Kipp W, Wild TC, Rubaale T, Okech J. Barriers to accessing highly active antiretroviral therapy by HIV positive women attending an antenatal clinic in a regional hospital in western Uganda. J Int AIDS Soc. 2010;13:37.

17. Kilian A. HIV/AIDS control in Kabarole District, Uganda, 2002. Available from: http://www.gtz.de/de/dokumente/en-gtz-hiv-preventionuganda.pdf. Accessed June 9, 2011.
18. Boyatzis R. Transforming Qualitative Information: Thematic Analysis and Code Development. Thousand Oaks, CA: Sage; 1998.

19. Rothe J. Undertaking Qualitative Research, 1st ed. Edmonton, Canada: University of Alberta Press; 2000.

20. Geddes R, Knight S, Reid S, Giddy J, Esterhuizen T, Roberts C. Prevention of mother-to-child transmission of HIV programmes: low vertical transmission in KwaZulu-Natal, South Africa. S Afr Med J. 2008;98(6):458-462.

21. Ciaranello AL, Seage GR, Freedberg KA, Weinstein MC, Lockman S, Walensky RP. Antiretroviral drugs for preventing mother-to-child transmission of HIV in sub-Saharan Africa: balancing efficacy and infant toxicity. AIDS. 2008;22(17):359-369.

22. Leroy V, Ekouevi DK, Becquet R, Viho I, Dequae-Merchadou L, Tonwe-Gold B. 18-months effectiveness of short course antiretroviral regimens combined with alternatives to breastfeeding to prevent HIV mother-to-child transmission. PLoS One. 2010;3(2):e1645.

23. Kumwenda J, Matchere F, Mataya R, et al. Coverage of highly active antiretroviral therapy among postpartum women in Malawi. Int J STD AIDS. 2011;22(7):368-372.

24. Theuring S, Nchimbi P, Jordan-Harder B, Harms G. Partner involvement in perinatal care and PMTCT services in Mbeya region, Tanzania: the provider's perspective. AIDS Care. 2010;22(12):1562-1568.

25. Bajunirwe F, Muzoora M. Barriers to the implementation of programs for the prevention of mother-to-child transmission of HIV: a cross-sectional survey in rural and urban Uganda. AIDS Res Ther. 2005;2:10.

26. Olley B, Seedat S, Stein D. Self-disclosure of HIV serostatus in recently diagnosed patients with HIV in South Africa. Afr J Reprod Health 2004;8(2):71-76.

27. Maman S, Mbwambo J, Hogan N, Kilonzo G, Sweat M. Women's barriers to HIV-1 testing and disclosure: challenges for HIV-1 voluntary counselling and testing. AIDS Care. 2001;13(5):595-603
International Journal of Women's Health

\section{Publish your work in this journal}

The International Journal of Women's Health is an international, peerreviewed open-access journal publishing original research, reports, reviews and commentaries on all aspects of women's healthcare including gynecology, obstetrics, and breast cancer. Subject areas include: Chronic conditions (migraine headaches, arthritis, osteoporosis);

\section{Dovepress}

Endocrine and autoimmune syndromes; Sexual and reproductive health; Psychological and psychosocial conditions. The manuscript management system is completely online and includes a very quick and fair peer-review system. Visit http://www.dovepress.com/ testimonials.php to read real quotes from published authors. 